This is an author produced version of a paper published in Metabolism.

This paper has been peer-reviewed but does not include the final publisher proof-corrections or journal pagination.

Citation for the published paper:

Shakir YA, Samsioe G, Nyberg P, Lidfeldt J, Nerbrand C.

"Does the hormonal situation modify lipid effects by

lifestyle factors in middle-aged women? Results from a populationbased study of Swedish women: the women's health in the Lund area study"

Metabolism, 2006, Vol: 55, Issue: 8, pp. 1060-66.

http://dx.doi.org/10.1016/j.metabol.2006.03.018

Access to the published version may require journal subscription. Published with permission from: Elsevier 


\title{
Does the Hormonal Situation Modify Lipid Effects by Lifestyle Factors in Middle Aged Women? \\ Results from a population based study of Swedish women. \\ The Women's Health in the Lund Area (WHILA) Study.
}

\author{
Yasameen A. Shakir MD ${ }^{1 *}$, Göran Samsioe MD, PhD ${ }^{1}$, Per Nyberg PhD², \\ Jonas Lidfeldt MD, $\mathrm{PhD}^{2}$, Christina Nerbrand $\mathrm{MD}, \mathrm{PhD}^{2}$
}

From the Departments of Clinical Sciences in Lund (1) and Malmö (2), Lund

University, Lund, Sweden

Proofs and Correspondence to: ${ }^{*}$

Yasameen A. Shakir * Department of Gynaecology and Obstetrics, Lund University Hospital, S-22185 Lund-Sweden.

E-mail: Yasameen.Shakir@med.lu.se

Fax: +46 46157868

\section{Running title}

Lipid effects by hormones in middle aged women is modified by lifestyle?

\section{Acknowledgements:}

The study was supported by grants from the Skane County Council Foundation for

Research and Development, and the Faculty of Medicine, Lund University. 


\section{Condensation}

The effects on the serum lipid profile by lifestyle factors depend on the hormonal

situation. This suggests interactions between female hormone and lifestyle factors in middle aged women. 


\section{Abstract}

Objectives: To outline whether the influence by lifestyle factors on serum lipids was modified by the hormonal situation in middle-aged women.

Methods: 6908 women aged 50-59 years, participated in a health assessment program, including a serum lipid profile evaluation. The women were grouped according to their hormonal status into premenopausal $(\mathrm{PM})(\mathrm{n}=492)$, postmenopausal without hormone therapy $(\mathrm{HT})(\mathrm{PM} 0)(\mathrm{n}=3600)$ and postmenopausal with HT (PMT) $(\mathrm{n}=2816)$. From the PMT group, we analysed oral (n $=901)$ and transdermal HT $(\mathrm{n}=351)$ regimens, containing norethisterone $($ NETA $)$ and 17 beta estradiol (E2). Serum lipids and lipoproteins were determined by conventional methods.

Lifestyle factors included smoking, physical activity at leisure time and at work.

Results: Multivariate linear regression analysis controlling for age, education and dietary habits, showed that current smoking was positively associated with triglycerides in the PM, PM0, PMT and oral HT. In the PM0, PMT and oral HT, current smoking was positively associated with total cholesterol and low-density lipoprotein (LDL) and negatively associated with high-density lipoprotein (HDL).

Low physical activity at leisure time was positively associated with triglycerides in the PM and PMT group and negatively associated with HDL in the PM0 and PMT groups.

High physical activity at work was positively associated with triglycerides in the PMT group and with total cholesterol in the PM0 group but negatively associated with HDL in the PMT and transdermal groups.

BMI (body mass index) was positively associated with triglycerides and negatively with HDL in all the groups regardless of the hormonal situation. 
Conclusions: The serum lipid profile as influenced by lifestyle factors was modified by the hormonal situation. Compared to the PM0 group, the use of HT contributes to fewer "negative" effects by lifestyle factors on serum lipids. 


\section{Introduction}

Coronary heart disease (CHD) is the most important cause of morbidity and mortality in the Western world. Perturbations of lipid metabolism are major contributors to atherosclerotic cardiovascular disease in general and to CHD in particular [1,2].

Prior to menopause, endogenous estrogens exert favourable effects on serum lipids. After menopause, the lipid profile changes towards atherogenicity [3].

The atherogenic lipid profile is due not only to the loss of hormones but also influenced by e.g. lifestyle factors. Advancing age and lifestyle factors like weight gain and smoking have been shown to induce an unfavourable low density lipoprotein/high density lipoprotein (LDL/HDL) cholesterol ratio, and to raise triglecerides and total cholesterol levels [4-6].

Compelling evidence from both prospective and retrospective observational studies suggests that estrogen monotherapy as well as sequential hormone therapy could reduce the risk of cardiovascular disease (CVD) in healthy postmenopausal women [7,8]. The mechanisms by which estrogen could confer protection are multiple [9]. Over the last few years, however, findings from large randomised primary and secondary prevention controlled trials of hormone therapy (HT) suggested that overall health risks exceeded benefits [10-11] with no appreciable cardiovascular benefit. Regular exercise reduces cardiovascular morbidity and mortality in the general population as well as in patients with CHD $[12,13]$. One contributing mechanism for this effect is the beneficial influence on plasma lipids. It is well documented that high density lipoprotein cholesterol (HDL) is increased with exercise [14, 15]. Prevention, not treatment, is the most feasible goal. Use of hormone replacement could be part of an over all strategy including lifestyle modification and other prevention measures, especially cessation of smoking [16]. 
To date a possible modification by the hormonal status on effects induced by lifestyle factors has not been studied in detail.

The aim of the present study was to outline if the influence by lifestyle factors on serum lipids was modified by the hormonal situation in middle-aged women.

Key words: Lipid profile, Hormone therapy, Lifestyle, middle-aged women. 


\section{Materials and Methods}

This report is an analysis of the project Women's Health in the Lund Area (WHILA). The Lund area is located in southern Sweden and composed of a university town with 100000 inhabitants, and its surrounding rural areas, mainly farmland with a population of $\sim 50000$ inhabitants.

The primary objectives of this project were to survey peri menopausal women in this area and to evaluate their health status, lifestyles, as well as social and medical risk factors for future disease. All women in the WHILA study were offered a health assessment programme that included a mailed generic self-administered questionnaire tied to certain laboratory examinations performed at a screening centre. Women who had findings indicative of disease received appropriate medical attention. The generic questionnaire contained 104 questions. Most of the questions had been used and validated previously [17-19]. After the subjects had filled out the questionnaire, a personal interview was carried out by a specially trained nurse-midwife to endorse and correct questionnaire replies. This resulted in one or more corrections in $19 \%$ of the questionnaires due mainly to thoughtless mistakes rather than to misunderstanding of the text.

Informed consent was obtained from participating subjects. The ethics committee at Lund University approved the study.

The WHILA project covered all women $(n=10766)$ who were born between December 2, 1935 and December 1, 1945, and living in the Lund area by December 1, 1995. The women were identified through a population register comprising all inhabitants. 


\section{Participants:}

Of total population 10766 women, $6908(64.2 \%)$ women completed the generic questionnaire and underwent a physical and laboratory assessment. The main reasons for non-response were: foreign nationality, having moved out of the community prior to the appointment given, refusal and death.

According to the hormonal situation, Participants $(\mathrm{n}=6908$ women) were divided into three groups, i.e. $7.1 \%(\mathrm{n}=492)$ were classified as pre-menopausal (PM) group, included the subjects who still had regular menstruation, $52.1 \%(\mathrm{n}=3600)$ were postmenopause without HT (PM0) group and 40.8\% ( $=2816)$ were postmenopausal women with ever HT user (PMT) group. Menopause was defined as a bleed-free interval of at least 12 months.

Among PMT group, several regimens of HT were used. In the present analysis, we analyzed current users of the two-combined oral regimen [continuous oral estradiol (E2) $2 \mathrm{mg}+$ norethisterone acetate (NETA) $1 \mathrm{mg}]+[$ sequential oral estradiol (E2) 2mg+ norethisterone acetate (NETA) 1mg] $(\mathrm{n}=901)$ and a transdermal patch

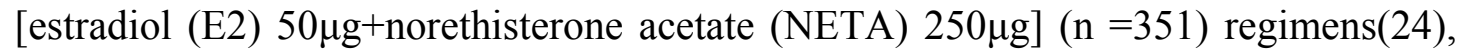
as by far these were the most commonly used regimens.

Apart from filling out the questionnaire, all women were also interviewed by a specially trained nurse-midwife about the questionnaire and the hormone use. For the interview, women were asked to bring packages of their current brand of HT and use of HT was as retained

\section{Laboratory variables:}

The baseline physical examination included measurements of body weight, body mass index (BMI) measured at the time of the screening. Serum levels of triglycerides, total cholesterol, high $-(\mathrm{HDL})$ and low (LDL) density lipoprotein cholesterol were 
measured on random blood sample with a Cholestech LDX -instrument (Cholestech Corporation, Hayward, CA, USA).

\section{Dietary habits}

Food intake was described in four categories:

Fat, fruit and vegetable, fiber, and cakes $\&$ sweets. The consumption was subdivided into high, moderate and low.

We divided the women into three groups using the sum of " less healthy diets" i.e. high fat (especially animal fat, but relatively low vegetable oil, high fat milk and meat, less fish, more sausages, bakeries and whip cream), low fruit and vegetable, low fibre ( less fiber rich bread and whole grain cereals) and high sweet contents (using extra sugar, eating sweets, cookies or other bakeries).

Healthy dietary habits: Women with healthy diet were defined as none or only one of the less healthy type of diet.

Unhealthy dietary habits: Women with unhealthy diet were defined as those with three or four less healthy diet types.

Intermediate dietary habits: Women that belonged to neither of the aforementioned categories

\section{Physical activity:}

The women answered questions about leisure physical activity, divided into low physical activity up to 2-4 hour/ week of light exercise (e.g. walking, dancing) and more intensive activity i.e. regular physical exercise 1-2 hour/week including vigorous training (e.g. running, swimming).

Physical activity at work during the last year was categorized into low, moderate and high physical intensity at work. Low referred to sedentary (white collar) work, moderate to mostly walking but not lifting heavily, and high to work with high degree 
of walking and lifting. Those without work during the last year were asked to categorize their work at home.

\section{Smoking}

Smoking was categorized by the life time consumption of pack-years. One pack-year corresponded to a consumption of 20 cigarettes per day for one year. Subjects were divided into three categories; never smokers ( $<1$ pack-year), past smokers and current smokers ( $\geq 1$ pack-year for both). Past smokers were those who had stopped smoking $\geq$ one month prior to the study.

\section{Statistical approach:}

For continuous variables judged as normally distributed Student's t-test and one-way ANOVA was used for determination of differences between groups. When not normally distributed, continuous variables were analysed using Mann-Whitney test and Kruskal-Wallis testBonferroni correction for multiple comparisons was applied with p-values $<0.017$ regarded as significant. . Pearson and, when applicable, Spearman correlation coefficients were calculated regarding BMI and lipid values. A multiple linear regression analyses controlling for age, educational level and dietary habits were performed to evaluate the influence of lifestyle factors (smoking, physical activity at leisure time and at work as well as BMI) on each of total cholesterol, HDL, LDL and triglycerides levels.

Dummy variables were constructed to show risk estimates related to unfavourable conditions. These dummy variables were smoking (current vs. never and past vs never), leisure time physical activity (low vs high), physical activity at work (high vs. low and moderate vs low). $\mathrm{p}$-values $\leq 0.05$ were regarded as statistically significant. Calculations were performed using the statistical program SPSS version 11.5 (SPSS Inc, Chicago, Illinois, USA). 


\section{Results:}

Baseline characteristics of each group are shown in the table 1.

As described before [20], levels of serum triglycerides, total cholesterol and LDL cholesterol were significantly higher in the PM0 than in the PMT and PM groups. HDL cholesterol level was significantly lower in PMT group than PM0 and PM groups. (data not shown)

Bivariate analysis (data not shown):

\section{Smoking habits:}

Total cholesterol, LDL and triglycerides were higher and HDL was lower among current smokers than past and never smokers in the PM0. These differences were same in the PMT group except there was no different in total cholesterol. In addition serum triglycerides were higher in current and past smokers than never smokers in the PM group. HDL was lower and LDL was higher in current smokers than past and never smokers in the oral HT group.

\section{Physical activity at leisure time:}

Serum triglycerides were lower and HDL were higher in women with high physical activity at leisure time in all five groups. Women in the PM group with high physical activity also had lower total cholesterol and LDL.

\section{Physical activity at work}

Total cholesterol was higher in women with high vs. low physical activity at work in the PM0 group. The same was found regarding triglycerides in the PM0, PMT and transdermal HT groups. HDL was lower in women with high vs. low physical activity at work in the transdermal HT group as well as was lower in high vs. moderate in the PM0 and PMT group. 


\section{Body mass index (BMI)}

BMI was positively correlated with LDL and triglycerides in all five groups. The same was true for total cholesterol with exception of the transdermal HT group. BMI was negatively correlated with HDL in all groups.

\section{Multiple linear regressions (tables 2A,B,C,D)}

Multivariate linear regression analyses, controlling for age, education and dietary habits showed that current smoking were positively associated with triglycerides in the PM, PM0, PMT and oral groups whereas the same association for past smoking in the PM and oral HT group was found. In the PM0, PMT and oral HT groups, current smoking was positively associated with total cholesterol and low-density lipoprotein (LDL) and negatively associated with high-density lipoprotein (HDL).

Low physical activity at leisure time was positively associated with triglycerides in the PM and PMT group and negatively associated with HDL in the PM0 and PMT groups.

High physical activity at work was positively associated with triglycerides in the PMT group and with total cholesterol in the PM0 group. It was negatively associated with HDL in the PMT and transdermal groups.

$\boldsymbol{B M I}$ was positively associated with triglycerides and negatively with HDL in all the groups regardless of the hormonal situation. 


\section{Discussion}

Serum lipids are influenced by several factors. Apart from sex steroids and BMI, life style factors such as smoking, physical activity at leisure time and at work have an impact. As lipids are influenced by several other lifestyle factors a stepwise linear regression was introduced to test the hypothesis if lifestyle factors could be modified by the hormonal situation.

\section{Smoking habits}

Among PM0 women the major effect by smoking seemed to be in lipids. This implies that loss of endogenously produced estrogens and progesterone exert an influence on cholesterol and triglycerides metabolism, which is seemingly different in current smokers and non-smokers. In essence, HDL particles are produced by the liver and the effect by smoking is therefore tentatively suggested to be mainly a hepatic process. The effect on LDL could be either indirect i.e. secondary to low HDL cholesterol or direct via an effect on LDL receptors. Cholesterol levels were minimally influenced by smoking in the PM group. Tentatively endogenous hormones eliminate the negative influence by smoking on cholesterol. The differences in plasma lipids between current smokers and non smokers were most abundant in the PM0 group.

Recently Mueck et al. [21] demonstrated that the reduction or loss of therapeutic efficacy is mainly caused by dose-dependent elevated hepatic clearance, partially in conjunction with lower estrogen levels, but this has been demonstrated only for oral estrogen applications. Furthermore smokers have less estrogenic influence than non smokers, one reason being a shift in the metabolism so that more estradiol is metabolized via 2 and 4 hydroxylation pathways of the A ring which give rise to a 
number of metabolites often referred to as cathecol estrogens with almost no estrogenic activity compared to metabolites produced by 16 hydroxy pathway [21]. The higher triglycerides in the PM0 group women could be a result either of increased triglycerides synthesis or decreased triglycerides removal. Low level of endogenous oestradiol seem to decrease triglycerides whereas higher levels, such as in pregnancy, clearly augment triglycerides. The loss of fairly low doses from the premenopausal to the postmenopausal status could explain the triglycerides increase. The mechanism behind this increase remains unknown but it is tentatively suggested that this is due to a lower peripheral lipoprotein lipase activity, which would be in line with a higher insulin resistance, which has been described before. Oral but not transdermal oestrogens are known to increase triglycerides but the concomitant administration of a progestogen, especially of the 19- norethisterone derivatives, such as norethisterone could result in unchanged or lowered triglycerides even in oral HT. It is also known that estradiol may increase insulin sensitivity and reduce insulin resistance. Smoking has been shown to have an opposite effect i.e. to increase insulin resistance. Smoking cessation, at least in men, is associated with a decrease in insulin resistance [22].

Godsland [23] reviewed studies on HT and lipids. Oral estrogens raised but transdermal estradiol 17-beta lowered triglycerides. However transdermal E2 has less an impact on cholesterol metabolism leaving HDL almost unchanged and less pronounced reduction of total and LDL cholesterol than oral therapy [23].

Indeed, one of our recent reports suggested that there is less an impact on the oral glucose tolerance test by transdermal compared to oral hormone therapy administration in women with feature of the metabolic syndrome [24].

High triglycerides are often linked to disturbances in carbohydrate metabolism. Again, this is probably a liver effect, which could be further underlined by the fact 
that the positive association between current smokers and total cholesterol, LDL and triglycerides and a negative one with HDL were seen in the oral HT users but not in transdermal HT users. The differences in various lipid fractions are consistent also with findings for bone mineral density [25].

\section{Physical activity at leisure time and at work}

Exercise is considered to be an effective way to lose weight as it promotes energy expenditure as well as metabolic rate and also alters body composition [26,27], and reduces insulin resistance. One study [28] reported that even small increases in physical activity at menopause might help to prevent adverse lipid changes and weight gain.

After controlling for confounding variables, multiple linear regression analysis showed that, low physical activity at leisure time mainly had a negative impact on triglycerides level in PM and PMT group and on HDL level in PM0 and PMT group . This in contrast to the physical activity at work showing that high activity had a negative impact on HDL in PMT and transdermal HT group and much less an influence on triglycerides as triglycerides tend to increase with physical activity at work at least in the PMT group. This increase is probably due to a concomitant increased intake of fat and other high caloric diets with high physical activity at work as high activity at work could tentatively be accompanied by a more stressful situation. To some extent this could also explain why blue-collar workers have a higher incidence of CVD than academics [29]. LDL cholesterol remains virtually, unaltered with physical activity at work and leisure time in all five groups.

\section{Body mass index(BMI)}

Excessive body fat is a problem faced by many postmenopausal women, and a common problem with obesity is inactivity. 
BMI seemed to be associated with higher triglycerides and lower HDL in all five groups of women (PM, PM0, PMT, oral and transdermal HT), and hence independent of the hormonal situation and mode of administration. Levels of lipoprotein lipase in adipose tissue are directly proportional to BMI; they affect the maintenance of fat, cell size, body weight and obesity [30]. Insulin resistance may also be the cause of high triglycerides, which lead to decreased HDL.

In randomised control trials, all participants receive very similar medical attention, which is not the case in observational studies. It is suggested that women who are prone to use HT had a healthier lifestyle than the non users [31], which in turn may contribute to many of the discrepancies between observational data and randomised control trial.

The present data demonstrate that the effects on the serum lipid profile by lifestyle factors depend on the hormonal situation. This suggests interactions between female hormone and lifestyle factors.

In general, lifestyle factors seem to be most important for the PM0 group and least important for the PM group with the PMT in between. Ideally the PMT group should be similar to the PM group but this seems not be the case. Hence there is room for improvement of HT regimens.

\section{Conclusions:}

The serum lipid profile as influenced by lifestyle factors seems to be modified by the hormonal situation.

Compared to the PM0 group, the use of HT contributes to fewer "negative" effects by lifestyle factors on serum lipids. Effects were still different between PM and PMT group. Hence existing hormone therapy regimens are still far from ideal. 
Transdermal route of HT seems to induce a different pattern compared to the oral group.

Further studies including biological markers are needed to further clarify these associations.

\section{References:}

[1] Castelli WP, Garrison RJ, Wilson PW, Abbott RD, Kalousdian S, Kannel WB. Incidence of coronary heart disease and lipoprotein cholesterol levels. The Framingham Study. JAMA. 1986;256(20):2835-8.

[2] Consensus Development Conference. Lowering blood cholesterol to prevent heart disease. JAMA 1985;253:2080-6.

[3] National Cholesterol Education Program 1993 Second Report of the Expert Panel on Detection, Evaluation and Treatment of High Blood Cholesterol in Adults ( Adults Treatment Panel II). Natl. Institutes of Health, Natl. Heart Lung and Blood Institute. NIH Publication No. 93-3095. Summary of the second report of the National Cholesterol Education Program (NCEP) Expert Panel on Detection, Evaluation, and Treatment of High Blood Cholesterol in Adults (Adult Treatment Panel II) JAMA. 1993 Jun 16;269(23):3015-23.

[4] Razay G, Heaton KW, Bolton CH. Coronary heart disease risk factors in relation to the menopause. Quart J Med New Ser 1992;85:307-8, 889-96.

[5] Poehlman ET, Toth MF. Ades PA, Rosen CJ. Menopause-associated changes in plasma lipids, insulin like growth factor I and blood pressure: a longitudinal study. Eur J Clin Invest 1997;4:322-6.

[6] Kannel WB. Metabolic risk factors for coronary heart disease in women: perspective from the Framingham study. Am Heart J 1987;114:413-9. 
[7] Barrett-Cannor E, Bush TL. Estrogen and coronary heart disease in women. JAMA 1991, 265:1861-1867.

[8] Grodstein F, Stampfer MJ, Manson JE, Colditz GA, Willett WC, Rosner B, et al. Postmenopausal estrogen and progestin use and the risk of cardiovascular disease. N Engl Med 1996, 335: 453-461.

[9] Mendelsohn ME, Karas RH. The protective effects of estrogen on the cardiovascular system. N Engl J Med 1999;340(23):1801-11.

[10] Grady D, Herrington D, Bittner V, Blumenthal R, Davidson M, Hlatky M, et al. Cardiovascular disease outcomes during $6 \cdot 8$ years of hormone therapy: Heart and Estrogen/ progestin Replacement Study follow-up (HERS II). JAMA 288 (2002), 49-57.

[11] The Writing Group for the Women's Health Initiative investigators. Risks and benefits of estrogen plus progestin in healthy postmenopausal women. JAMA $2002 ; 288: 321-33$.

[12] Paffenbarger R.S., Hyde R.T., Wing A.L, Lee I. The association of changes in physical activity level and other lifestyle characteristics with mortality among men. N. Engl. J. Med. 1993; 328, 538-454.

[13] Blair, S.N., Kohl III, H.W., Barlow, C.E., Paffenbarger, R.S. Changes in physical fitness and all cause mortality. Aprospective study of healthy and unhealthy men. JAMA.1995;273:1093-1098.

[14] Brussaard HE, Gevers Leuven JA, Kluft C, Krans HM, van Duyvenvoorde W, Buytenhek R, et al. Effects of 17 beta-estradiol on plasma lipids and LDL oxidation in postmenopausal women with type II diabetes mellitus. Arterioscler. Thromb Vasc. Biol. 1997; 17(2), 324-330. 
[15] Duncan JJ, Gordon NF, Scott CB. Women walking for health and fitness. How much is enough? JAMA. 1991:;266, 3295-3299.

[16] Hu FB, Stampfer MJ, Manson JE, Grodstein F, Colditz GA, Speizer FE et al. Trends in the Incidence of Coronary Heart Disease and Changes in Diet and Lifestyle in Women. NEJM. 2000; 343(8):530-537.

[17] Nerbrand C, Lidfeldt J, Nyberg P, Schersten B, Samsioe G. Serum lipids and lipoproteins in relation to endogenous and exogenous female sex steroids and age. The Women's Health in the Lund Area (WHILA) study. Maturitus. 2004;48:161169.

[18] Lidfeldt J, Nyberg P, Nerbrand C, Samsioe G, Schersten B, Agardh CD. Socio-demographic and psychosocial factors are associated with features of the metabolic syndrome. The Women's Health in the Lund Area (WHILA) study. Diabetes Obes Metab. 2003 Mar;5(2):106-12.

[19] Li C, Samsioe G, Lidfeldt J, Nerbrand C, Agardh CD. Important factors for use of hormone replacement therapy. A population based study of Swedish women. The Women's Health in Lund Area (WHILA) study. Menopause. 2000; 7(4): 273-281.

[20] Yasameen A. Shakir, Göran Samsioe, Per Nyberg, Jonas Lidfeldt, Christina Nerbrand. Cardiovascular risk factors in middle-aged women and the association with use of hormone therapy: results from a population-based study of Swedish women. The Women's Health in the Lund Area (WHILA) Study. Climacteric. 2004 Sep;7(3):274-83.

[21] Mueck AO, Seeger H. Smoking, estradiol metabolism and hormone replacement therapy. Curr Med Chem Cardiovasc Hematol Agents. 2005;3(1):4554. 
[22] Eliasson B, Attvall S, Taskinen MR, Smith U. Smoking cessation improves insulin sensitivity in healthy middle-aged men. Eur J Clin Invest. 1997;27(5):4506

[23] Godsland IF. Effects of postmenopausal hormone replacement therapy on lipid, lipoprotein, and apolipoprotein (a) concentrations: analysis of studies published from 1974-2000. Fertil Steril 2001 May; 75(5): 898-915.

[24] Yasameen A. Shakir, Göran Samsioe, Christina Nerbrand, Jonas Lidfeldt. Combined hormone therapy in postmenopausal women with features of metabolic syndrome. Results from a population-based study of Swedish women: Women's Health in the Lund Area study. Menopause. 2004 ;11(5):549-55.

[25] Jensen J, Christiansen C. Effect of smoking on serum lipoproteins and bone mineral content during postmenopausal hormone replacement therapy. Am J Obstet Gynecol 1988; 159: 820-25.

[26] Meredith CN, Zackin MJ, Frontera WR, Evans W.J. Body composition and aerobic capacity in young and middle aged endurance-trained men. Med. Sci. Sports Exerc. 198719, 557-563.

[27] Mole PA, Stern JS, Schultz CL, Bernauer EM. Exercise reverses depressed metabolic rate produced by severe caloric restriction. Med. Sci. Sports Exerc. 1989;21:29-33.

[28] Owens JF, Matthews KA, Wing RR, Kuller LH. Can physical activity mitigate the effects of aging in middle aged women? Circulation 1992;85:12651270.

[29] Emberson JR, Whincup PH, Morris RW, Walker M. Social class differences in coronary heart disease in middle-aged British men: implications for prevention. Int J Epidemiol. 2004;33(2):289-96. 
[30] Eckel R.H. Lipoprotein lipase. A multifunctional enzyme relevant to common metabolic disease. N. Engl. J. Med. 1989;320:1060-1068.

[31] Matthews KA, Kuller LH, Wing RR, Meilahn EN, Plantinga P. Prior to use of estrogen replacement therapy, are users healthier than nonusers? Am $J$ Epidemiol. 1996; 143(10):971-8. 


\section{Legends of tables}

\section{Table 1}

Baseline characteristics of groups in different hormonal status groups (premenopausal women (PM), post-menopausal women not use HT (PM0) and postmenopausal women with ever use of HT (PMT), and in different groups concerning mode of adminstration of hormone therapy (Transdermal and oral groups).

\section{Table 2A}

The association of lifestyle factors (smoking, physical activity at leisure time and at work and BMI) with triglycerides in different hormonal status groups (premenopausal women (PM), post-menopausal women not use HT (PM0) and postmenopausal women with ever use of HT (PMT), and in different groups concerning mode of administration of current hormone therapy (Transdermal and oral groups). Multiple linear regression analysis controlling for age, education and dietary habits.

NS: non significant

\section{Table 2B}

The association of lifestyle factors (smoking, physical activity at leisure time and at work and BMI) with high-density lipoprotein $H D L$ in different hormonal status groups(pre-menopausal women (PM), post-menopausal women not use HT (PM0) and post-menopausal women with ever use of HT (PMT), and in different groups concerning mode of administration of current hormone therapy(Transdermal and oral groups). Multiple linear regression analysis controlling for age, education and dietary habits.

NS: non significant 


\section{Table 2C}

The association of lifestyle factors (smoking, physical activity at leisure time and at work and BMI) with total cholesterol in different hormonal status groups(premenopausal women (PM), post-menopausal women not use HT (PM0) and postmenopausal women with ever use of HT (PMT), and in different groups concerning mode of administration of current hormone therapy(Transdermal and oral groups). Multiple linear regression analysis controlling for age, education and dietary habits.

NS: non significant

\section{Table 2D}

The association of lifestyle factors (smoking, physical activity at leisure time and at work and BMI) with low-density lipoprotein $L D L$ in different hormonal status groups (pre-menopausal women (PM), post-menopausal women not use HT (PM0) and postmenopausal women with ever use of HT (PMT) and in different groups concerning mode of administration of hormone therapy(Transdermal and oral groups). Multiple linear regression analysis controlling for age, education and dietary habits.

NS: non significant 
Table 1

\begin{tabular}{|c|c|c|c|c|c|}
\hline & $\operatorname{PM}(n=492)$ & $\operatorname{PMO}(n=3600)$ & $\operatorname{PMT}(n=2816)$ & Transdermal HT(n=351) & Oral HT(n=901) \\
\hline Age(years); mean (SD) & $53.2(1.6)$ & $56.9(2.9)$ & $56.2(2.8)$ & $55.7(2.5)$ & $56.6(2.8)$ \\
\hline \multicolumn{6}{|l|}{ Education (\%) } \\
\hline comprehensive education & 9.7 & 22.5 & 14.0 & 14.0 & 12.2 \\
\hline secondary education & 40.5 & 47.1 & 48.2 & 43.9 & 50.5 \\
\hline university education & 49.8 & 30.4 & 37.8 & 42.2 & 37.4 \\
\hline \multicolumn{6}{|c|}{ Physical activity at work (\%) } \\
\hline sedentary work & 42.4 & 33.0 & 37.9 & 39.0 & 36.9 \\
\hline light activity work & 36.3 & 38.2 & 39.2 & 39.6 & 39.6 \\
\hline heavy activity work & 21.3 & 28.8 & 23.0 & 21.4 & 23.5 \\
\hline \multicolumn{6}{|l|}{ Smoking habit (\%) } \\
\hline Never smokers & 66.1 & 64.8 & 64.0 & 62.1 & 62.9 \\
\hline Past smokers & 19.7 & 16.8 & 21.3 & 21.1 & 21.0 \\
\hline Current smokers & 14.2 & 18.4 & 14.7 & 16.8 & 16.1 \\
\hline $\begin{array}{l}\text { High physical activity at } \\
\text { leisure time(\%) }\end{array}$ & 47.8 & 41.0 & 43.1 & 46.3 & 44.2 \\
\hline \multicolumn{6}{|l|}{ Dietary habit (\%) } \\
\hline Healthy & 41.5 & 39.6 & 42.4 & 48.7 & 39.5 \\
\hline Unhealthy & 21.8 & 26.9 & 25.2 & 25.1 & 25.5 \\
\hline Intermediete & 36.7 & 33.4 & 32.4 & 26.3 & 35.0 \\
\hline
\end{tabular}




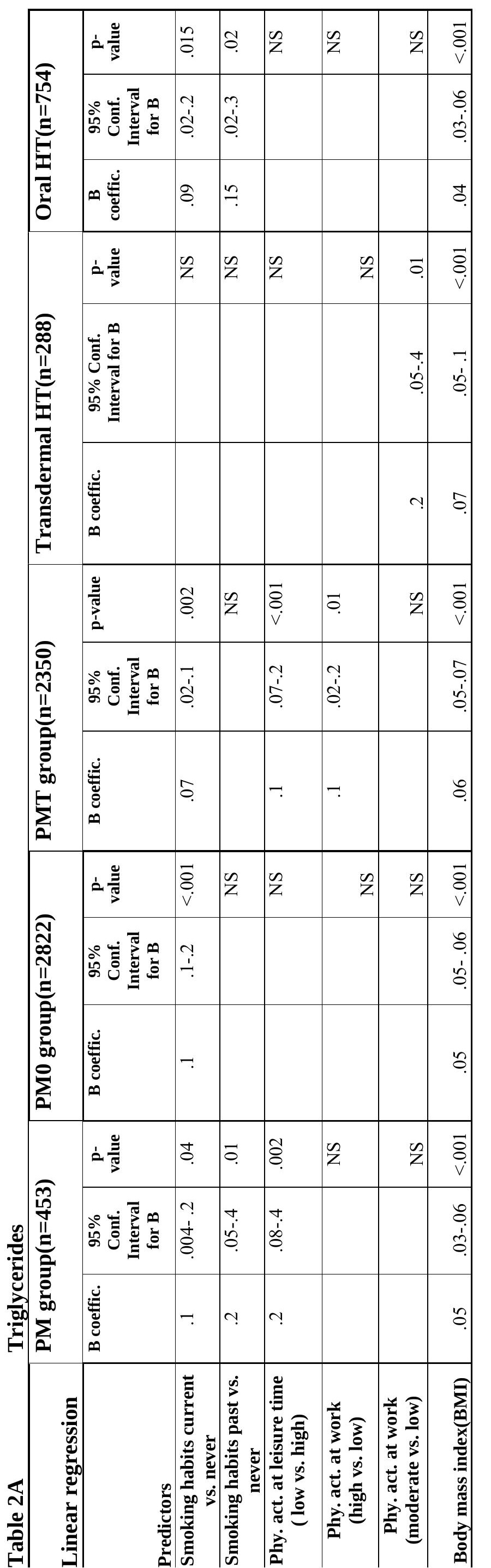




\begin{tabular}{|c|c|c|c|c|c|c|c|}
\hline \multirow{3}{*}{ 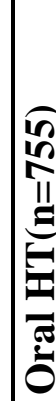 } & $\dot{\partial}$ & $\begin{array}{l}\overrightarrow{8} \\
v\end{array}$ & $\tilde{z}$ & $\bar{z}$ & $\bar{z}$ & $\tilde{z}$ & $\begin{array}{l}\vec{b} \\
\dot{b} \\
v\end{array}$ \\
\hline & هُ & $\mid \begin{array}{c}8 \\
i \\
i \\
i\end{array}$ & & & & & 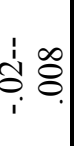 \\
\hline & م) & $\vec{i}$ & & & & & $\vec{c}_{i}$ \\
\hline \multirow{3}{*}{ 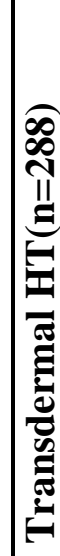 } & 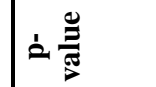 & $\tilde{z}$ & $\tilde{z}$ & $\tilde{z}$ & ธิ. & $\tilde{z}$ & t. \\
\hline & 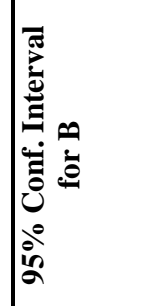 & & & & $\begin{array}{l}0 \\
0 \\
i \\
1 \\
0 \\
0 \\
i\end{array}$ & & $\begin{array}{l}\Im \\
0 \\
i \\
\vdots \\
i\end{array}$ \\
\hline & ه & & & & 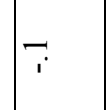 & & ô. \\
\hline \multirow{3}{*}{ 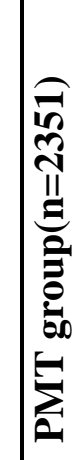 } & 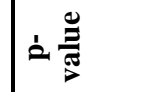 & $\overrightarrow{\vec{\partial}}$ & $\bar{z}$ & 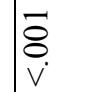 & $\overline{0}$. & $\tilde{z}$ & $\begin{array}{l}\vec{z} \\
\dot{v} \\
\end{array}$ \\
\hline & 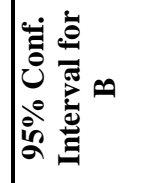 & $\mid \begin{array}{l}0 \\
0 \\
i \\
0 \\
0 \\
i\end{array}$ & & $\begin{array}{l}\hat{o} \\
i \\
i \\
0 \\
0 \\
i\end{array}$ & 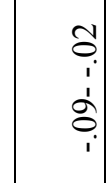 & & $\begin{array}{c}0 \\
\vdots \\
\vdots \\
0 \\
\vdots\end{array}$ \\
\hline & 我离 & $\stackrel{0}{\circ}$ & & $\stackrel{0}{0}$ & $\stackrel{n}{i}$ & & $\stackrel{s}{i}$ \\
\hline \multirow{3}{*}{ 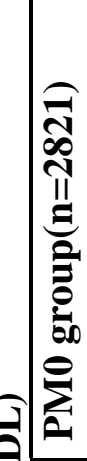 } & 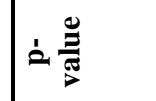 & $\overrightarrow{\mathrm{a}}$ & $\frac{n}{z}$ & $\widehat{\mathrm{z}}$ & $\tilde{z}$ & $\tilde{z}$ & $\begin{array}{l}\bar{b} \\
\dot{v}\end{array}$ \\
\hline & 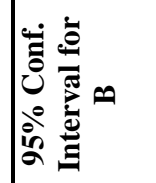 & 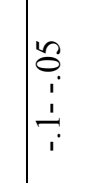 & & $\begin{array}{l}0 \\
0 \\
i \\
0 \\
o \\
0 \\
i\end{array}$ & & & $\begin{array}{c}0 \\
0 \\
\vdots \\
\vdots \\
0 \\
i\end{array} \mid$ \\
\hline & 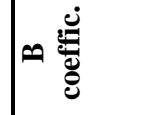 & $\hat{s}_{i}$ & & $\overbrace{i}$ & & & o \\
\hline & 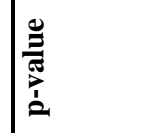 & $\underline{z}$ & $\tilde{z}$ & $\tilde{z}$ & $\tilde{z}$ & $\tilde{z}$ & $\vec{s}$ \\
\hline : & 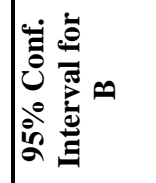 & & & & & & $\begin{array}{l}0 \\
\vdots \\
\vdots \\
\vdots \\
i\end{array}$ \\
\hline$\sum_{2}^{5}$ & م) & & & & & & 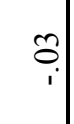 \\
\hline & & 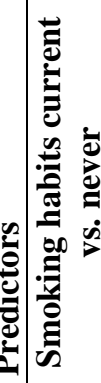 & 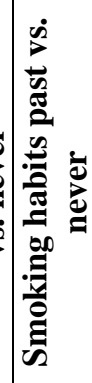 & 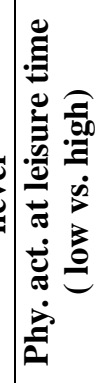 & 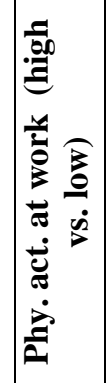 & 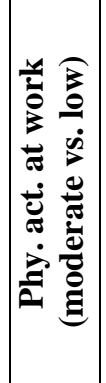 & 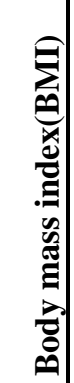 \\
\hline
\end{tabular}




\begin{tabular}{|c|c|c|c|c|c|c|c|}
\hline \multirow{3}{*}{ 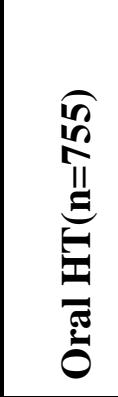 } & 之莺 & ठै. & $\tilde{Z}$ & $\tilde{z}$ & $\tilde{Z}$ & $\tilde{Z}$ & $\tilde{\delta}$ \\
\hline & صْ & 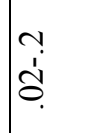 & & & & & $\begin{array}{l}n \\
\vdots \\
i \\
0\end{array}$ \\
\hline & ص & - & & & & & $\delta$ \\
\hline \multirow{3}{*}{ 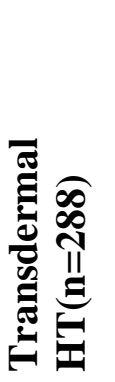 } & L' & $\tilde{z}$ & $\tilde{z}$ & $\bar{z}$ & $\bar{z}$ & $\tilde{Z}$ & $\tilde{Z}$ \\
\hline & صْ & & & & & & \\
\hline & ه & & & & & & \\
\hline \multirow{3}{*}{ 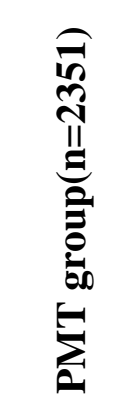 } & D立 & ô. & $\tilde{z}$ & $\tilde{z}$ & $\bar{z}$ & $\tilde{z}$ & $\overline{8}$ \\
\hline & صَّ & - & & & & & $\begin{array}{l}\dot{J} \\
\vdots \\
\dot{\delta}\end{array}$ \\
\hline & ص & $\hat{0}$ & & & & & ô. \\
\hline \multirow{3}{*}{ 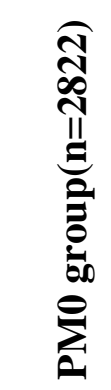 } & ¿ & $\stackrel{\infty}{8}$ & & in. & ¿ & & $\delta$ \\
\hline & صَّ & ¿. & & $\frac{8}{8}$ & r. & & 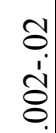 \\
\hline & ص & $\hat{0}$ & & $\stackrel{\infty}{0}$ & oे. & & o \\
\hline \multirow{4}{*}{$\theta$} & 立 & $\tilde{Z}$ & $\tilde{z}$ & $\tilde{Z}$ & $\tilde{Z}$ & $\tilde{Z}$ & $\bar{Z}$ \\
\hline & صُ & & & & & & \\
\hline & 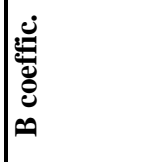 & & & & & & \\
\hline & 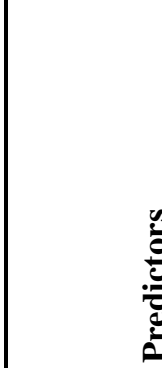 & 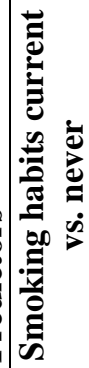 & 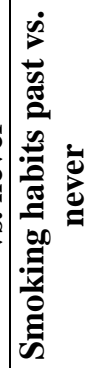 & 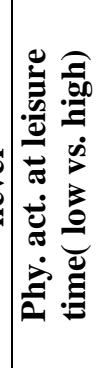 & 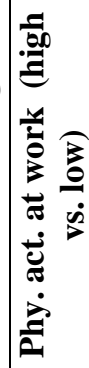 & 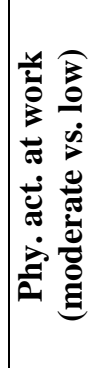 & 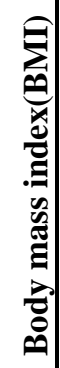 \\
\hline
\end{tabular}


